\title{
Thyroid Imaging Reporting and Data System (TIRADS) Versus Thyroid Scan for Solitary Thyroid Nodules
}

\author{
HAYTHAM M. NASSER, M.D.* and MOHAMMED ALEEM, M.D.** \\ The Departments of Radiology* and Otorhinolaryngology**, Faculty of Medicine, Ain Shams University, Cairo, Egypt
}

\begin{abstract}
Background: Solitary Thyroid nodules are a common finding which is defined as localized thyroid enlargement within an otherwise apparently normal gland. It is more common in females. Most of them are asymptomatic usually accidently discovered in neck US or carotid Doppler. Solitary thyroid nodule has a higher risk for malignancy than multiple nodules as reported in literature. Previously Radioactive Isotope scanning was first line for characterization before FNAC which is the gold standard to exclude malignancy. The availability and safety of US in addition to marvelous technological advances that yields high diagnostic power made it a prefect tool for the initial characterization of thyroid nodules. Recently TI-RADS (Thyroid Imaging Reporting and Data System) were proposed on the basis of ultrasound features for initial Solitary thyroid nodule characterization.
\end{abstract}

Aim of Study: To compare between Thyroid Imaging Reporting and Data System and thyroid scan to evaluate the malignant potentiality of the solitary thyroid nodule with taking reference the results of fine needle aspiration cytology (FNAC) and histopathology as gold standard.

Material and Methods: Thirty patients were enrolled in our cross section study with solitary thyroid nodule referred from the Otolaryngology Department to Radiology Department at Ain Shams University Hospitals. All patients underwent full thyroid ultasound examination with full comment on the nodules as regarde shape, echogenicity, margins, internal components and echogenic foci and classified according to the Americal college of radiology (ACR) Thyroid Imaging Reporting and Data System (TIRADS) Classification guideline, then thyroid scan was done to all cases. Results of both ultrasound and thyroid scan are compared with histopathological results of Fine needle aspiration cytology (FNAC).

Results: The sensitivity and specificity of TIRADS on considering TR4 and TR5 lesions positive ( suspiciuos) when compared with histopathological findings were $100 \%$ and $79.2 \%$ respectively with PPV of $54.5 \%$, NPV of $100 \%$ and accuracy of $83.3 \%$. While isotope sensitivity when considering a cold nodule to be positive (suspiciuos) was $66.7 \%$ with specificity of $16.7 \%$, PPV of $20 \%$, NPV of $66.7 \%$ and accuracy of $26.7 \%$.

Conclusion: Our results suggest that ACR TIRADS classification is superior to thyroid scan as regarde charchterization of solitary thyroid noude and considered reliable in predicting thyroid malignancy.

Correspondence to: Dr. Haytham M. Nasser, E-Mail: Hmnh1980@gmail.com
Key Words: Ultrasonography - Solitary thyroid nodule - ACR - TIRADS - FNAC - Thyroid scintigraphy.

\section{Introduction}

THYROID nodules are a very common finding, and there is increase in its detection with the marvelous technological advances in ultrasound which is widely available [1]. Thyroid nodules are common with prevalence rate ( $20 \%$ to $76 \%$ ), and it is more common in females and incidence increase by age [2]. Most of the thyroid nodules are asymptomatic usually accidently found in neck US or carotid Doppler. Neck US and carotid Doppler is done using linear high frequency probe, recent advances in ultrasound technology yield probes with very high resolution detecting small lesions up to $1 \mathrm{~mm}$ as regard cystic lesion and up to 2-3 $\mathrm{mm}$ as regard solid lesions. The availability and safety of US in addition to the previously mentioned fact of high diagnostic power made it a prefect tool for the initial diagnosis and characterization of thyroid nodules [3]. Solitary thyroid nodules are defined as solitary localized thyroid enlargement within an otherwise apparently normal gland. Solitary thyroid nodule gains its importance for attention from the fact reported in literature, solitary thyroid nodule has a higher risk of malignancy than multiple nodules. Since then surgeons tend to treat them with degree of the suspicion with the need of preoperative treatment plan which is usually based on FNAC histopathology. Solitary thyroid nodules are common, being present in up to $50 \%$ of the elderly population [6]. In view of the fact that only about $7 \%-15 \%$ of cases are found to malignant so it was mandatory to establish a variety of examinations to differentiate between benign and malignant thyroid nodules [3] . Currently, fineneedle aspiration (FNA) is considered the gold standard examination to differentiate between malignant and benign lesion for future treatment plan [5]. However, the invasive nature of the procedure together with the unnecessary patients 
anxiety adding to this the financial burden of the FNAC, it is found to be unpractical to biopsy all patient with solitary thyroid nodules [4]. Previously Radioactive Isotope scanning using either Iodine 123 or technetium Tc $99 \mathrm{~m}$ pertechnetate was used to classify nodules into either nonfunctioning (cold) or functioning (warm or hot) nodules. Only 5 to $15 \%$ of the cold nodules are malignant $[1,8]$ As the cost of radioactive isotope scan is increasing it was mandatory to find another cheaper method with comparable diagnostic value. Several trials were done by multiple professional societies to propose examinations other than thyroid scan to guide in the management plan of thyroid nodules. Recently TI-RADS (Thyroid Imaging Reporting and Data System) were proposed to guide ultrasound practitioners in recommending FNA on the basis of ultrasound features [9]. The TI-RADS, was established based on sonographic characters of thyroid nodule, such as nature (solid or cystic), echogenicity, irregular margins, calcifications, and orientation [10].

\section{Aim of work:}

The purpose of this study is to compare the positive predicative value and the negative predictive value of both thyroid scan and TI-RADS (TR4 and TR5) as regard solitary thyroid nodule with reference to FNAC histopathology.

\section{Patients and Methods}

\section{Patients:}

During a period from March 2018 to October 2018, 30 patients were enrolled in the study referred to Radiology Department at Ain Shams Main University Hospitals. All patients with solitary thyroid nodule diagnosed by ultrasound. Regarding TIRADs classification, we allocated TIRADs (1-3) in a group (negative with low risk) and TIRADs (4-5) as another group (positive with high risk) in the mean time all patient underwent thyroid scintigraphy and also classified into two groups. first group with function nodule (hot or worm) with low risk and cold nodule with high risk. And then all results are compared with histopathological results to study the sensitivity, specificity, PPV and NPV of both techniques.

\section{Inclusion criteria:}

- Patients with solitary thyroid nodule diagnosed by U/S.

- No age predilection.

- No sex predilection.

\section{Exclusion criteria:}

- Bleeding tendency.

- Multinodular goiter.
- Patient with past history of thyroid surgery (sub total or total with recurrent nodule).

- Patient with pathologically proven malignant nodule.

\section{Ethical consideration:}

An informed consent is obtained from the patient concerning the complication of the procedure, the complication of the radioactive material, FNAC procedure and the acceptance to be enrolled in the study.

\section{Procedure:}

Each patient is subjected to full history taking and clinical examination, Ultrasound examination of the thyroid was done, characterization of the thyroid nodule according to American College of Radiology (ACR) TIRADS classification (Table 1). All patients underwent thyroid scan. Classification of thyroid nodule into functioning (worm and hot) and non functioning (cold). Correlation of the result of both TIRADS classification and thyroid scan with further histopathological examination of nodules by FNAC.

Table (1A,B): American college of radiology thyroid imaging reporting and data system (TIRADS) classification and recommendations [9]

Table (1A): US evaluation of solitary thyroid nodule.

\begin{tabular}{|c|c|}
\hline Feature & Description and points \\
\hline Shape (choose 1) & $\begin{array}{l}\text { Wider than tall } \\
0 \text { points } \\
\text { Taller than wide } \\
3 \text { points }\end{array}$ \\
\hline Margin (choose 1) & $\begin{array}{l}\text { Smooth or ill-defined } \\
0 \text { points } \\
\text { Lobulated or irregular } \\
2 \text { points } \\
\text { Extrathyroidal extension } \\
3 \text { points }\end{array}$ \\
\hline Composition (choose 1) & $\begin{array}{l}\text { Cystic or almost completely cystic } \\
0 \text { points } \\
\text { Spongiform } \\
0 \text { points } \\
\text { Mixed cystic and solid } \\
1 \text { point } \\
\text { Solid or almost completely solid } \\
2 \text { points }\end{array}$ \\
\hline Echogenicity (choose 1) & $\begin{array}{l}\text { Anechoic } \\
0 \text { points no FNA } \\
\text { Hyperechoic or isoechoic } \\
1 \text { point } \\
\text { Hypoechoic } \\
2 \text { points } \\
\text { Very hypoechoic } \\
3 \text { points }\end{array}$ \\
\hline $\begin{array}{l}\text { Echogenic foci } \\
\text { (choose all that apply) }\end{array}$ & $\begin{array}{l}\text { None or large comet-tail artifacts } \\
0 \text { points } \\
\text { Macrocalcifications } \\
1 \text { point } \\
\text { Peripheral (rim) calcifications } \\
2 \text { points } \\
\text { Punctate echogenic foci } \\
3 \text { points }\end{array}$ \\
\hline
\end{tabular}


After evaluation of solitary thyroid nodule summation of points is done to determine TI-RADS grade as follow.

Table (1B)

\begin{tabular}{ll}
\hline Points & TI-RADS grade \\
\hline 0 points & TR1 \\
2 points & TR2 \\
3 points & TR3 \\
$4-6$ points & TR4 \\
$>7$ points & TR5 \\
\hline
\end{tabular}

Data management and analysis:

Data were coded and entered using the statistical package SPSS (Statistical Package for the Social Sciences) version 23.

\section{Results}

In our study, 30 patients were enrolled $22 \mathrm{fe}$ males $(73.33 \%)$ and 8 males $(26.67 \%)$. The mean age group was 42.40 years \pm 10.67 years. All patients had single nodule and underwent U/S with TIRADs classification, isotope scan and FNAC. The results showed that 24 nodules $(80 \%)$ were cold by isotope scan and 6 nodule $(20 \%)$ were functioning (Table 1). 24 nodules $(80 \%)$ were benign by FNA and 6 nodule $(20 \%)$ were malignant (Table 2). According to TIRADS classification 5 nodules $(16.6 \%)$ were TR $1,1(3.3 \%)$ nodule was TR2, 13 nodules $(43.3 \%)$ where TR3, 4 nodule $(13.3 \%)$ were TR4 and 7 nodule $(23.3 \%)$ were TR5 (Table 3).

\section{Classifiication of nodules by isotope scan:}

Table (2): Showing isotope findings.

\begin{tabular}{cc} 
Cold nodule & Functioning nodule \\
\hline 24 & 6 \\
\hline
\end{tabular}

\section{Classification of noudles by FNA:}

Table (3): Showing FNA results.

\begin{tabular}{cc}
\hline Benign nodule & Malignant nodule \\
\hline 24 & 6 \\
\hline
\end{tabular}

Classification of nodules according to TIRADS:

Table (4): Showing TIRADS classification of the nodules.

\begin{tabular}{ll}
\hline TR1 & 5 \\
TR2 & 1 \\
TR3 & 13 \\
TR4 & 4 \\
TR5 & 7 \\
\hline
\end{tabular}

Table (5): Showing the number of nodules considered to be negative (TR1, TR2 and TR3 nodules) and the number of nodules considered to be positive (TR4 and TR5 nodules).

\begin{tabular}{cc} 
TIRADS negative & TIRADS positive \\
\hline 19 & 11 \\
\hline
\end{tabular}

Table (6): Showing the correlation between TIRADS and FNA results as well as istope findings and FNA results.

\begin{tabular}{|c|c|c|c|c|c|}
\hline & \multicolumn{2}{|c|}{ Pathology } & \multirow{3}{*}{$\begin{array}{c}\text { Test } \\
\text { value* }\end{array}$} & \multirow{3}{*}{$\begin{array}{c}p- \\
\text { value }\end{array}$} & \multirow{3}{*}{ Sig. } \\
\hline & Benign & Malignant & & & \\
\hline & No. $(\%)$ & No. $(\%)$ & & & \\
\hline \multicolumn{6}{|l|}{ ACR TIRADS: } \\
\hline Negative & $19(79.2 \%)$ & $0(0.0 \%)$ & 12.955 & 0.000 & HS \\
\hline Positive & $5(20.8 \%)$ & $6(100.0 \%)$ & & & \\
\hline \multicolumn{6}{|l|}{ Isotope: } \\
\hline Functioning & $4(16.7 \%)$ & $2(33.3 \%)$ & 0.833 & 0.361 & NS \\
\hline Cold & $20(83.3 \%)$ & $4(66.7 \%)$ & & & \\
\hline
\end{tabular}

Table (7): Showing TIRADS and isotope sensitivity and specificity.

\begin{tabular}{lccccc}
\hline & \multicolumn{5}{c}{ Pathology } \\
\cline { 2 - 6 } & $\begin{array}{l}\text { Sensi- } \\
\text { tivity }\end{array}$ & $\begin{array}{l}\text { Speci- } \\
\text { ficity }\end{array}$ & PPV & NPV & Accuracy \\
\hline ACR TIRADS & $100.0 \%$ & $79.2 \%$ & $54.5 \%$ & $100.0 \%$ & $83.3 \%$ \\
Isotope & $66.7 \%$ & $16.7 \%$ & $20.0 \%$ & $66.7 \%$ & $26.7 \%$ \\
\hline
\end{tabular}



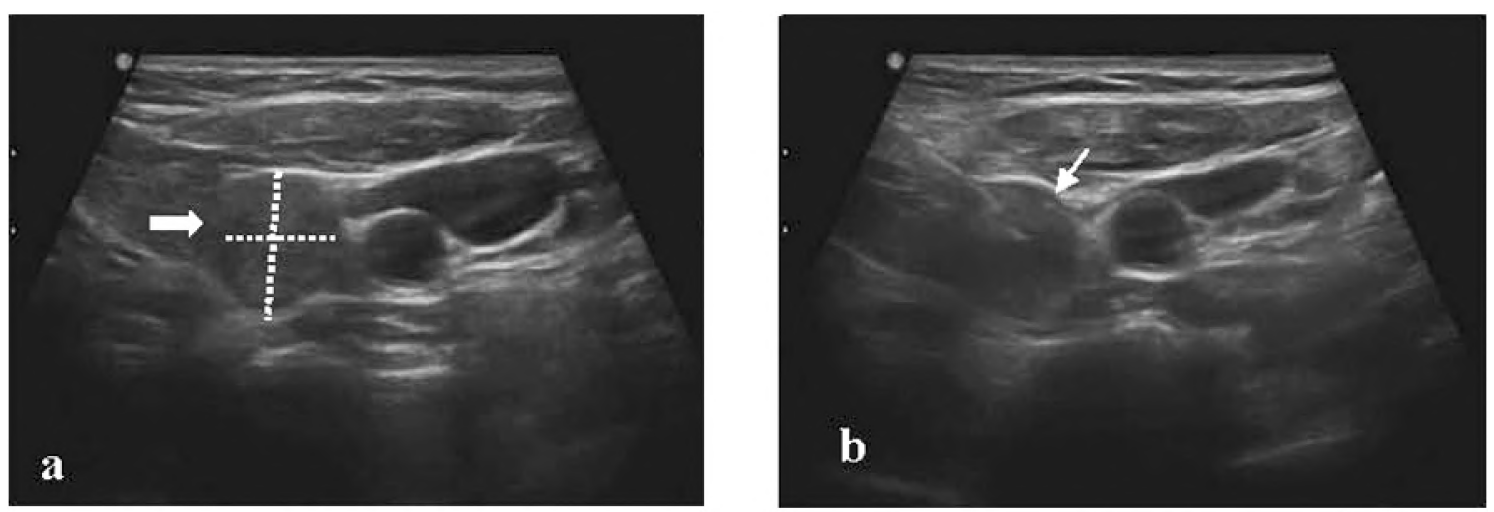

Fig. (1): US of solitary thyroid nodule. (A) Solid nodule (2 points), taller than wider dotted line (3 points), iso/hypoechoic (2 points), ill defined lobulated margin wide arrow (2 points). (B) Macrocalcification narrow arrow (1 point) TR 5 with a needle in the nodule for FNA.
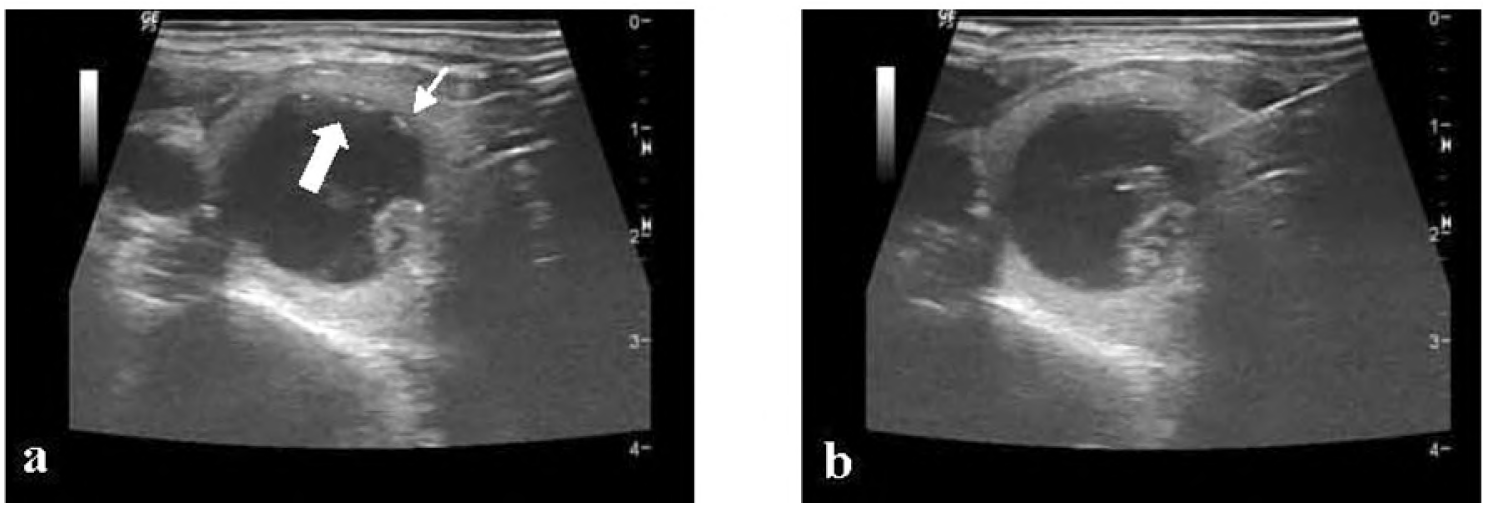

Fig. (2): US of solitary thyroid nodule. (A) Partially cystic partially solid nodule (1 points), iso/hyperechoic (1 points), lobulated margin wide arrow ( 2 points) pperipheral calcification narrow arrow ( 2 point) TR 4. (B) A needle in the nodule for FNA.

\section{Discussion}

Fine needle aspiration is a minimally invasive efficient technique for solitary thyroid nodule characterization which can efficiently differentiate between benign and malignant $[1,11,12]$. Many authors have shown that fine needle aspiration is the most sensitive cost effective and specific method to characterize solitary thyroid nodule $[13,14]$ In spite of the presence of multiple studies supporting fine needle as a cost effective diagnostic test for solitary thyroid nodule, Yet the invasive nature of FNA increase patient fear from the procedure in addition to its financial burden it was mandatory to find an initial characterization method to avoid unnecessary FNA. Many clinicians still considering thyroid scintigraphy as the primary diagnostic tool of choice for initial characterization of thyroid nodule. The continuation of this management strategy likely attributed to historical practice pattern in some institutes $[\mathbf{1 5 , 1 6}]$. Comparative studies between TIRADS, scintigraphy and FNAC would be beneficial short pathway for faster shift from traditional management strategies.
In our study, we compared TIRADS result to thyroid scintigraphy as regard sensitivity, specificity, PPV and NPV with referencing to FNAC as considered the gold standard. Regarding the sensitivity and specificity of TR4 and TR5 lesions when compared with histopathological findings were $100 \%$ and $79.2 \%$ respectively with PPV of $54.5 \%$, NPV of $100 \%$ and accuracy of $83.3 \%$. On the other hand, isotope sensitivity when considering a cold nodule to be malignant was $66.7 \%$ with specificity of $16.7 \%$, PPV of $20 \%$, NPV of $66.7 \%$ and accuracy of $26.7 \%$. Mohandas et al., results were quite similar to us when he mentioned that TIRADs sensitivity was $85.7 \%$ and specificity was $68 \%$ with accuracy of $69.2 \%$ [17]. Also, Basharat et al., results concerning the sensitivity and specificity of thyroid scan when compared with FNA results were $80 \%$ sensitivity and $20 \%$ specificity, PPV $10 \%$, NPV $90 \%$ and accuracy of $26 \%$ [18]

\section{Study limitations:}

A limitation of this study is that it's of relative small sample size. It would be beneficial to conduct another study on larger number of patients. Another 
limitation was the absence of inter observer analysis as it was done by one radiologist. This study is a single-center study; larger multicenter is study is recommended for confirmation of our results.

\section{Conclusion:}

ACR TIRADS classification is a reliable examination for characterization of thyroid nodules which can replace the classic thyroid scan test which was readily used for thyroid nodule characterization. TIRADS has higher specificity, sensitivity positive predictor value and negative predictive value which can significantly decrease number of unneeded FNAC decreasing patient anxiety and financial burden and avoiding invasive nature of FNAC. We strongly recommend more studies as regard this issue to ensure higher level of evidence and may also introduce any suggestion for modification of TIRADS to increase specificity and sensitivity. As usage of US in TIRADS classification made it readily available, recordable, reproducible and cheaper.

\section{References}

1- COOPER D.S., DOHERTY M.G., HAUGEN B.R., HAUGER B.R., KLOOS R.T., LEE S.L., et al.: American Thyroid Association (ATA) Guidelines Taskforce on Thyroid Nodules and Differentiated Thyroid Cancer. Thyroid, 19: 1167-214, 2009.

2- GHARIB H., PAPINI E., PASCHKE R., DUICK D.S., VALCAVI R., HEGEDÜS L., et al.: American Association of Clinical Endocrinologists, Associazione Medici Endocrinologi, and European ThyroidAssociation Medical Guidelines for Clinical Practice for the Diagnosis and Management of Thyroid Nodules. Endocr. Pract, 16: 143, 2010.

3- HORVATH E., SILVA C. F., MAJLIS S., RODRIGUEZ I., SKOKNIC V., CASTRO A., ROJAS H., NIEDMANN J.P., MADRID A., CAPDEVILLE F., WHITTLE C., ROSSI R., DOMÍNGUEZ M. and TALA H.: Prospective validation of the ultrasound based TIRADS (Thyroid Imaging Reporting and Data System) classification: Results in surgically resected thyroid nodules. European Radiology, 1-10, 2016.

4- XIE C., COX P. TAYLOR N. and LAPORTE S.: Ultrasonography of thyroid nodules: A pictorial review. Insights into Imaging, 7 (1): 77-86, 2016.

5- DAVIES L. and WELCH H.G.: Current thyroid cancer trends in the United States. JAMA Otolaryngol. Head Neck Surg., 140: 317-322, 2014.

6- JENA A., PATNAYAK R., PRAKASH J., SACHAN A., SURESH V. and LAKSHMI A.Y.: Malignancy in solitary thyroid nodule: A clinicoradiopathological evaluation. Indian Journal of Endocrinology and Metabolism, 19 (4): 498-503, 2015.
7- NGGADA H., MUSA A., GALI B. and KHALIL M.: "Fine needle aspiration cytology of thyroid nodule (S): A Nigerian tertiary hospital experience", Internet Journal of Pathology, Vol. 5, No. 1, 2006.

8- LAWRENCE Jr. W. and KAPLAN B.J.: "Diagnosis and management of patients with thyroid nodules", Journal of Surgical Oncology, Vol. 80, No. 3, pp. 157-170, 2002.

9- TESSLER F.N., MIDDLETON W.D., GRANT E.G., HOANG J.K., BERLAND L.L., TEEFEY S.A., CRONAN J.J., BELAND M.D., DESSER T.S., FRATES M.C., HAMMERS L.W., HAMPER U.M., LANGER J.E., READING C.C., SCOUTT L.M. and STAVROS A.T.: ACR Thyroid Imaging, Reporting and Data System (TI RADS): White Paper of the ACR TI-RADS Committee. Journal of the American College of Radiology, 44 (0): 143-151, 2017.

10- WEI X., LI Y., ZHANG S. and GAO M.: Meta-analysis of thyroid imaging reporting and data system in the ultrasonographic diagnosis of 10,437 thyroid nodules Head \& Neck, 38 (2): 309-315, 2016.

11- TABAQCHALI M.A., HANSON J.M., JOHNSON S.J., WADEHRA V., LENNARD T.W.J. and PROUD G.: "Thyroid aspiration cytology in Newcastle: A six year cytology/histology correlation study", Annals of the Royal College of Surgeons of England, Vol. 82, No. 3, pp. 149155,2000

12- NASUTI J.F., GUPTA P.K. and BALOCH Z.W.: "Diagnostic value and cost-effectiveness of on-site evaluation of fine-needle aspiration specimens: Review of 5,688 cases," Diagnostic Cytopathology, Vol. 27, No. 1, pp. 1-4, 2002.

13-CAPPELLI C., PIROLA I., GANDOSSI E., de MARTINO E., AGOSTI B. and CASTELLANO M.: "Fine-needle aspiration cytology of thyroid nodule: Does the needle matter?" Southern Medical Journal, Vol. 102, No. 5, pp. 498-501, 2009.

14- MOSLAVAC S., MATESA N. and KUSI'C, Z.: "Thyroid fine needle aspiration cytology in children and adolescents", Collegium Antropologicum, Vol. 34, No. 1, pp. 197-200, 2010.

15- AGRAWAL S.: "Diagnostic accuracy and role of fine needle aspiration cytology in management of thyroid nodules," Journal of Surgical Oncology, Vol. 58, No. 3 , pp. 168-172, 1995.

16- MATHUR S.R., KAPILA K. and VERMA K.: "Role of fine needle aspiration cytology in the diagnosis of goiter", Indian Journal of Pathology and Microbiology, Vol. 48, No. 2, pp. 166-169, 2005.

17- MOHANDAS M., NADARAJAN S., HUBERT N. and JOSE L.: Diagnostic accuracy of TIRADS in evaluation of thyroid nodules, January 7, 2019.

18- BASHARAT R., BUKHARI M.H., SAEED S. and HAMID T.: Comparison of Fine Needle Aspiration Cytology and Thyroid Scan in Solitary Thyroid Nodule. Pathology Research International, 1-9, 2011. 


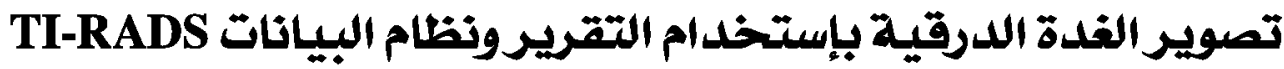

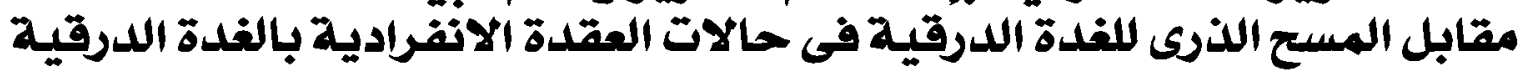

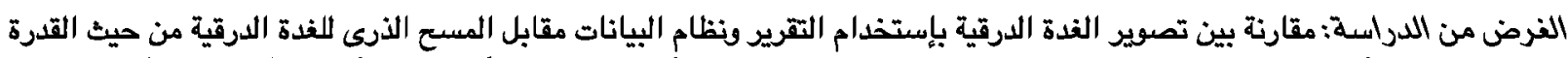

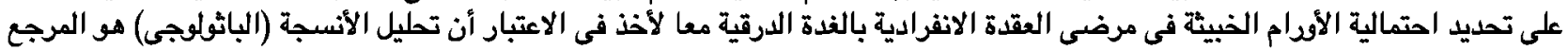

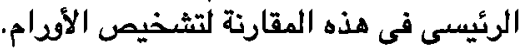

المواد والطرق : تم تعجيل لثلاثى مريضاً في دراستتا يعانون من العقدة الانفرادية بالغدة الدرقية محلمف من تسم الأنف والأذن والصنجرة

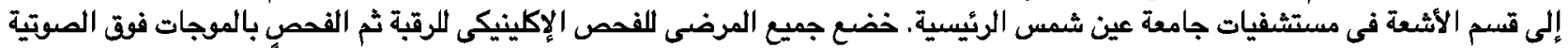

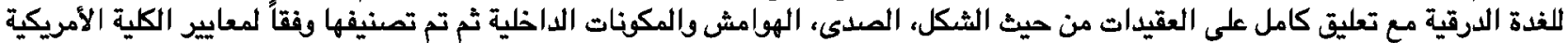

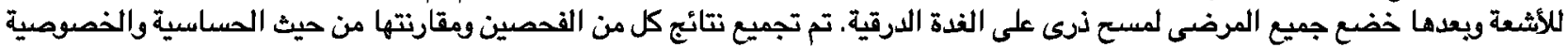

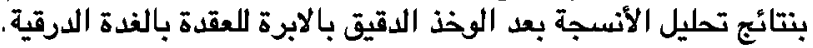

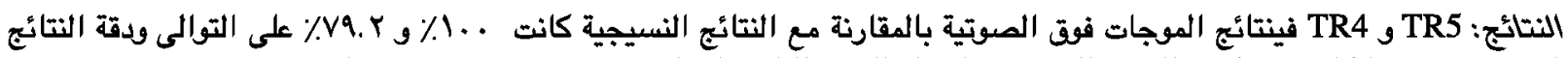

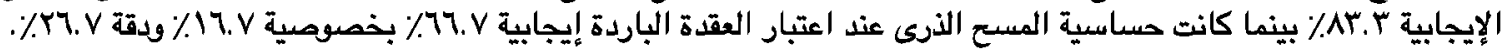
الخخلاصة: محصلة نتائج البمث أن تصوير الغدة الدرقية بأستخدام التقرير ونظام البيانات يمكن مقارنته بالمسيح الذرى للغدة الدرقية ويعتبر

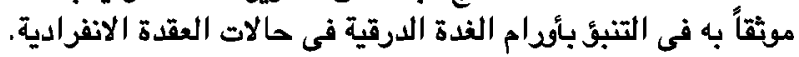

